\title{
A FRACTAL ACCELERATOR ON THE BASIS OF A CORRUGATED PLASMA WAVEGUIDE WITH SUPERCONDUCTING WALLS
}

\author{
I.V. Tkachenko ${ }^{1}$, V.I. Tkachenko ${ }^{1,2}$ \\ ${ }^{1}$ National Science Center "Kharkov Institute of Physics and Technology”, Kharkiv, Ukraine; \\ ${ }^{2}$ V.N. Karazin Kharkiv National University, Kharkiv, Ukraine \\ E-mail: tkachenko@kipt.kharkov.ua
}

The use of a two-stage mechanism for the acceleration of charged particles is proposed. The principle of acceleration is based on the use of the fractal properties of the wave spectrum of a corrugated plasma waveguide with superconducting walls. The first stage provides for the excitation of a corrugated plasma waveguide by short electron bunches in the direction of motion (the length of the bunch is significantly less than the period of the corrugation). On the second stage the test charged particles accelerates in an infinite number of harmonics of the electric field exited by an electron bunches. Calculations show that with the implementation of such an acceleration mechanism, the average speed of a non-relativistic test particle can increase several times, and its acceleration length can be up to one meter.

PACS: 52.40.Fd; 52.40.Mj

\section{INTRODUCTION}

The term wakefield acceleration indicates that Cherenkov radiation [1], propagating behind the particle in a medium or a slowing structure, is used to accelerate a low-current bunch to higher energies [2].

Currently, this method of acceleration is the subject of intensive research (see, for example, [3, 4]) and in this direction quite encouraging results have been obtained.

However, the investigations of the wakefield acceleration in periodic plasma waveguides (for example, corrugated sinusoidally) remain an open question concerning accounting of the full set of radial and longitudinal electric fields harmonics.

Typically, one or more resonant [2] eigenmodes are taken into account from an infinite number them, and the rest is neglected because of assumptions about their weak interaction with the accelerated particles.

In fact, unaccounted waves, despite their small contribution to the acceleration of charged particles, can greatly change the dispersion of the plasma waveguide $[5,6]$.

Therefore, the study of taking into account of the full spectrum of a superconducting corrugated waveguide with plasma filling to accelerate charged particles is, as before, a very topical issue.

The task is to indicate the plasma and corrugated waveguide parameters, which would ensure the acceleration of charged particles over the shortest interaction length.

To solve this problem, it is necessary, first, to study the dispersion properties of the waveguide structure, which takes into account absolutely all eigenmodes, and, secondly, to study their interaction with accelerated charged particles.

When considering the latter issue, the problem of excitation of such waveguides, for example, by charged particles, is to be solved and then the excited wave spectrum utilization for the acceleration of the test charged particles may be proposed.

According to the method of excitation of a longitudinal electric field in a plasma, the proposed method of acceleration can be referred to as the bunch method [2].
Therefore, we restrict ourselves to considering just such an acceleration scheme: we describe the dispersion properties of corrugated plasma waveguides, investigate the possibility of their excitation by electron bunches, and finally consider the possibility of using such systems to accelerate test charged particles.

\section{FEATURES OF THE DISPERSION PROPERTIES OF CORRUGATED PLASMA WAVEGUIDES}

The study of the dispersion properties of waveguides with an ideally conducting metal wall, corrugated according to the law $H(z)=a\left(1+\alpha \cos \left(k_{0} z\right)\right)$ and filled with plasma (here $L_{0}=2 \pi / k_{0}$ is a corrugation period, $\alpha=\frac{b}{a}$ is a corrugation parameter; $b$ is a corrugation depth, $2 a$ is a transverse size of the waveguide) showed the formation of a dense wave spectrum [7 - 9].

This means that in the phase space at any deliberately selected point with coordinates $\left(\omega_{0}, q_{0}\right)$, where: $\omega=\omega_{0}, k_{3}=q_{0}$ both the frequency and the longitudinal wave number, there exists an infinite number of waves.

In this case, a charged particle that moves in such medium with a velocity $V_{0}$, will resonantly interacts with an infinite number of longitudinal waves, that satisfy the requirement of phase matching $V_{0}=\omega_{0} / q_{0}$, and are characterized by both longitudinal $q_{0}$ and transverse $k_{\perp}=\frac{\pi}{2 a}+\frac{l \pi}{a}$ wave numbers (case of flat geometry, $l=0 ; \pm 1 ; \pm 2 ; \ldots, K, K-$ integer).

Although the excited waves are polarized due to the discrete nature of the wave spectrum (their phase velocity is equal to $V_{\phi}$, and the group wavelength is zero), the presence of the transverse component of the wave vector gives them the character of Cherenkov waves [1]. Moreover, the velocity of the particle must satisfy the condition: $V_{0}>V_{\phi} \frac{q_{0}}{k_{\perp}}$. 
The resonant nature of particles interaction with the waveguide eigenwaves requires that the parameter $\Delta_{m}$ introduced in [10 - 13] should be considered zero. In addition, depending on which of the forbidden bands of the corrugated plasma waveguide the frequency $\omega_{0}$ falls, it is necessary to take into account the corresponding decrement $d\left(\omega_{0}\right)$, which is proportional to the depth of the corrugation $\alpha$ (in the opacity band, the amplitude of wave $A$ decays according to the law $A=A_{0} e^{-d t}$ ). In this case, the reactive bunch instabilities [10 - 12] may change to dissipative $[11,14]$, which is non-threshold, and is characterized by smaller values of increments.

Thus, to study the acceleration of charged particles in corrugated plasma waveguides with superconducting walls, it is necessary to study the problem of the resonant interaction of charged particles with a plasma in the presence of a dense wave spectrum.

\section{ANALYSIS OF THE EXCITED WAVE SPECTRUM OF A CORRUGATED PLASMA WAVEGUIDE}

Lets consider a two-step scheme for the acceleration of charged particles in an infinite corrugated plasma waveguide.

The first step is the excitation of a corrugated plasma waveguide with a short electron bunch in the direction of the particles longitudinal movement (the length of the bunch is significantly less than the period of the corrugation).

The second step is the acceleration of test charged particles in an electric field excited by an electron bunch of an infinite number of harmonics.

Calculations of the dispersion properties of a flat plasma filled corrugated waveguide, carried out in [7 9], allow us to imagine the strength of the longitudinal electric field $E_{z}$. in the form:

$$
E_{z}(r, z, t)=\sum_{n=-\infty}^{\infty} a_{n} f_{n}(r) e^{i k_{3 n} z-i \omega t},
$$

where $a_{n}$ - harmonic amplitudes; $f_{n}(r)$ - membrane functions that describe the transverse distribution of the electric field strength and all are equal to 1 at $r \rightarrow 0$; $k_{3 n}=k_{3}+n k_{0} ; k_{3}-$ longitudinal wave number; $\omega-$ wave frequency.

Let us consider the excitation of a field in the form (1) and determine the possibility of setting the coefficients $a_{n}$ necessary for acceleration. The method of incomplete numerical simulation can show that a short electron bunch which parameters correspond to the parameters of a very narrow forbidden band in a corrugated plasma waveguide (decrement $d\left(\omega_{0}\right)$ is small compared to the bunch instability increment) excites wave (1), but with special conditions for the coefficients $a_{n}$ : a sufficiently large number of these coefficients coincide with each other (Fig. 1). This statement can be justified by a series of simple transformations of the expression for the field (1). As a result of such transformations, it is easy to obtain the following total $\delta$-functional dependence of the electric field intensity on time:

$$
E_{z}\left(0, z_{0}, t\right)=E_{0} e^{-i \omega t} \sum_{n=-\infty}^{\infty} \delta\left(t-t_{n}\right)
$$

where $E_{0}$ is the amplitude, generally weakly dependent on time.

In expression (2), due to the smallness of the contribution, the balance of the sum, which is determined by the coefficients of expression (1) remaining from the first sum, not equal to each other, is omitted.

In Fig. 1 shows the temporal dynamics of the electric field strength at a particular point in space, obtained by the method of incomplete numerical simulation, similar to the calculations carried out in [2] and the sources cited there. It can be seen that the periodic amplitude pulsations are of sufficient magnitude to approximate them by a sum of $\delta$-functional dependencies.

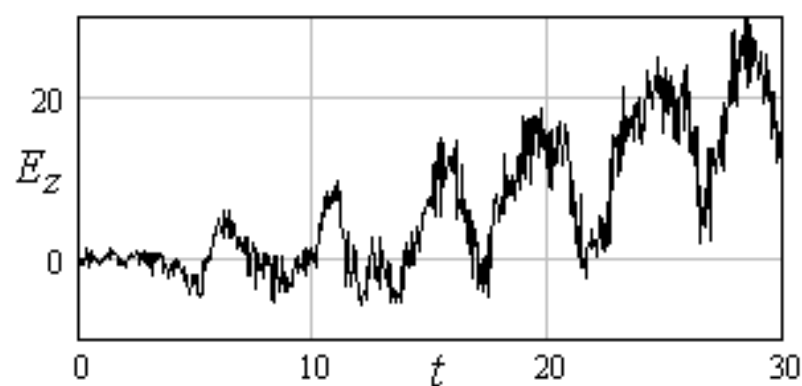

Fig. 1. The temporal dynamics of the electric field strength at a single point in space $\zeta$ with the number of modes $M=100$, the absorption index $d=0.01$

Thus, when a short electron bunch moves in a corrugated plasma waveguide, a spectrum (1) is excited, in which $K$ harmonics can be equal to each other. From the mathematical point of view, this possibility arises because in the infinite determinant obtained in the study of the dispersion properties of a flat corrugated plasma waveguide, the term $K$ coincides. In the case when $K>>1(1 / K-$ the multiplicity points of the intersection of the dispersion curves $[8-10])$, the infinite sum of harmonics can be represented as an infinite sum $\delta$ functions. In expression (2), the amplitude $E_{0}$ is the amplitude of $K$ harmonics, $t_{n}$ - the time that determines the passage of the $n$-th period of the waveguide by the bunch.

\section{ANALYSIS OF THE CORRUGATED PLASMA WAVEGUIDE EXCITED WAVE SPECTRUM}

Now, after the accelerating field (2) is determined, let's consider the motion of a test positively charged particle with the mass $m_{i}=\Lambda \cdot m_{e}$ (where $\Lambda \gg 1$ ) in this field. The change in time of its coordinates $\zeta$ near the axis of the waveguide is described by the equation:

$$
\frac{d^{2} \zeta}{d \tau^{2}}=\Lambda^{-1} \mathcal{E}_{0} \sum_{n=-\infty}^{\infty} e^{i\left(k_{3} / k_{0}+n\right) \zeta-i\left(\Omega / \omega_{0}\right) \tau},
$$

where $\tau=\omega_{0} t, \zeta=z k_{0}, \quad \mathcal{E}_{0}=\frac{2 \pi e k_{0} E_{0}}{m_{e} \omega_{0}^{2}}, \quad \Omega=\omega_{0}-i \Delta \omega$, $\omega_{0}-$ is the frequency at which the intersection of an infinite number of dispersion curves of a corrugated 
plasma waveguide is observed, $\Delta \omega-$ the width of the forbidden band, which corresponds to the frequency $\omega_{0}$, $k_{3}$ - is the longitudinal wave number. We assume that the decrement is small, and in the calculations should be assumed to zero.

Equation (3) in a view as the above can be reduced to the form:

$$
\frac{d^{2} \zeta}{d \tau^{2}}=\Lambda^{-1} \varepsilon_{0} e^{i\left(\frac{k_{3}}{k_{0}} \zeta-i \tau+i \frac{\Delta \omega}{\omega_{0}} \tau\right)} \sum_{n=-\infty}^{\infty} \delta(\zeta(\tau)-2 \pi n) .
$$

Let's find a solution to this equation.

First of all, we note that in the time intervals $\tau_{k}<\tau<\tau_{k+1}$, where $\tau_{k}$ is determined from the equation $\zeta\left(\tau_{k}\right)=2 \pi k$, the test particle moves with a constant velocity, the dimensionless value of which we denote as $V_{k}=w_{k} / V_{0}$, where $w_{k}$ is a test particle's velocity in the interval $\tau_{k}<\tau<\tau_{k+1}, V_{0}$ is the initial velocity of the test particle. At time $\tau_{k}$, the velocity abruptly changes from $V_{k}$ to $V_{k+1}$. The relationship between these velocities can be obtained from equation (4) by performing its integration within $\tau_{k}-\varepsilon<\tau<\tau_{k}+\varepsilon, \quad \varepsilon<<\left(\tau_{k+1}-\tau_{k}\right)$ and then directing the small parameter $\varepsilon$ to zero. As a result, one can get a recurrent relation that determines the test particle's velocity at each of the acceleration intervals:

$$
V_{k+1}=V_{k}+\frac{\Lambda^{-1} \varepsilon_{0}}{V_{k}} \exp \left(-\frac{\Delta \omega}{\omega_{0}} \frac{2 \pi k}{V_{k}}\right) \cdot \cos \left(\frac{k_{3}}{k_{0}} 2 \pi k-\frac{2 \pi k}{V_{k}}\right) .
$$

In an infinite corrugated plasma waveguide, the parameter $k_{3} / k_{0}$ can take any value less than one, i.e. it is determined by its fractional part (if the parameter $k_{3} / k_{0}$ is greater than one, then the integer part will be subtracted due to the periodicity of the function, the argument of which it is). Therefore, in further calculations, we will assume this parameter to be less than one.

Fig. 2 shows the graphs of the growth rate of a test positively charged particle's velocity as a function of distance, measured by the number of periods of a corrugated plasma waveguide $k$. In the calculations, the following parameters of the accelerating system were chosen: $\Lambda^{-1} \boldsymbol{E}_{0}=0.15 ; \Delta \omega / \omega_{0}=0.02$.

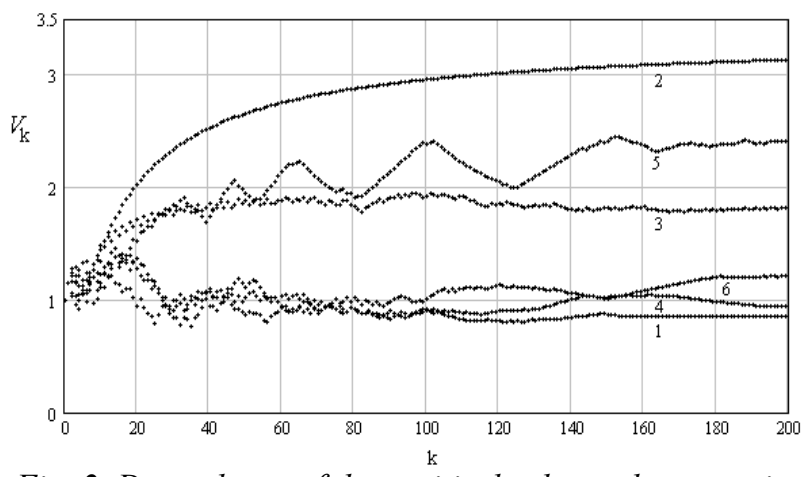

Fig. 2. Dependence of the positively charged test particle's velocity at the distance $L=L_{0} k$ versus

of the parameter value: $1-\chi=0.1 ; 2-\chi=0.3$;

$3-\chi=0.5 ; 4-\chi=0.7 ; 5-\chi=0.9 ; 6-\chi=0.0$

(numbering of curves is located under the corresponding curves)
It can be seen from the figure that acceleration is more efficient near one parameter value $\chi=0.3$. For other values of the parameter $\chi$, either a lower acceleration rate or a decrease in the initial velocity is observed, i.e. there is a deceleration.

Thus, the above example confirms the possibility of the two-step mechanism for the acceleration of charged particles in a plasma waveguides with a superconducting corrugated walls. In this case, the non-relativistic dimensionless velocity of the test particle may increase several times.

\section{THE INVESTIGATION OF THE TWO-STEP METHOD OF CHARGED PARTICLES ACCELERATION}

For a more detailed analysis of the proposed twostep acceleration of charged particles, we use the method of incomplete numerical simulation, which has recently been used to study the generation of electromagnetic waves in plasma waveguides [10 - 14].

In our case, we will investigate the motion of particles of two types in the plasma in the presence of a large number of waves. In the longitudinal direction, we assume the plasma is unlimited, and we exclude transverse boundary from consideration due to a strong external magnetic field, which allows the use of a onedimensional description of the motion of charged particles. For this, it is necessary that the condition $\omega_{e}=e H_{0} / m_{e} c>>\Omega_{e}=\left(4 \pi e^{2} n_{0 e} / m_{e}\right)^{1 / 2}$ to be fulfilled where $n_{0 e}$ is equilibrium plasma density; $m_{e}$ is the electron mass; $H_{0}$ is external magnetic field intensity; $c$ is the speed of light.

First, we define the type of electromagnetic field that will be excited, and then accelerate the particles. The wave packet in plasma is represented as the sum of a large number of waves that move with different phase velocities:

$$
E(z, t)=\sum_{m=1}^{M} E_{m}(t) \sin \left[k_{m} z-\omega_{m} t+\phi_{m}(t)\right] .
$$

Here $M>>1$ is a large number of modes that propagate in the plasma; $E_{m}, \omega_{m}, k_{m}, \varphi_{m}$ are an amplitude of electric field, frequency, wave number and phase of the $m$-th mode.

We consider the electric field intensity in the form that takes into account only resonant harmonics. To do this, we assume that $\omega_{m}=m \Delta \omega_{0}, \quad k_{m}=m \Delta k_{0}$ $(m=1 \ldots M)$, where $\Delta \omega_{0}, \Delta k_{0}$ are the conditional size of the perturbation waveform partitioning; $\Delta k_{0}$ is chosen in such a way that the relation $\Delta k_{0} V_{0}=\Delta \omega_{0}$ is fulfilled. Due to such transformations, we obtain the expression for the wave packet:

$$
E(z, t)=\sum_{m=1}^{M} E_{m}(t) \sin \left[m \Delta k_{0}\left(z-V_{0} t\right)+\phi_{m}(t)\right] .
$$

The system of equations that describes the time variation of the amplitudes and phases of the electric field (6) can be obtained by substituting the results of integrating the equations of plasma particles motion into the 
Poisson equation using the harmonic oscillation method [10 - 12].

Considering the above, we can write the equations (in dimensionless variables) which describe the interaction between the wave spectrum of the corrugated plasma waveguide and charged particles (electrons and positive charged test particles):

$$
\begin{aligned}
\frac{d \boldsymbol{E}_{m}}{d \tau} & =\frac{1}{N} \cdot \sum_{i=1}^{N} \sin \left(m \xi_{i}+\phi_{m}\right)-d\left|\mathcal{E}_{m}\right|, \\
\frac{d \phi_{m}}{d \tau} & =\frac{1}{\mathcal{E}_{m} \cdot N} \cdot \sum_{i=1}^{N} \cos \left(m \xi_{i}+\phi_{m}\right),
\end{aligned}
$$

where $\tau=k_{0} V_{0} \beta^{1 / 3} t, \varepsilon_{m}=\frac{E_{m} k_{0} \beta^{2 / 3}}{4 \pi e n_{o b}}, \beta=n_{o b} / n_{o e}<<1-$ is the ratio of the equilibrium density of the bunch and plasma, respectively. Charged particles are modeled using $N$ layers moving with velocity $V_{0}(1 \leq i \leq N, i-$ is the layer number), the coordinate of which is given in the form $\xi_{i}=\Delta k_{0}\left(z_{i}-V_{0} t\right)$.

The system of equations (7), (8) must be supplemented by equations that describe the motion of charged particles of a bunch (in dimensionless variables):

$$
\frac{d^{2} \xi_{i}}{d \tau^{2}}=\left\{\begin{array}{l}
-\sum_{m=1}^{M} \varepsilon_{m} \sin \left(m \xi_{i}+\phi_{m}\right), \quad 1 \leq i \leq N_{1}, \\
\Lambda^{-1} \cdot \sum_{m=1}^{M} \varepsilon_{m} \sin \left(m \xi_{i}+\phi_{m}\right), \quad N_{1}+1 \leq i \leq N .
\end{array}\right.
$$

Equations (9) describe the motion of electrons (upper expression on the right side of (9)) and positively charged test particles with mass $\Lambda$ and quantity $N_{2}$ (lower expression on the right side of (9)). The total number of charged particles is $N: N_{1}+N_{2}=N$.

From the equations (7)-(9) in the absence of absorption can be obtained the integral $I$ which was helped us to control the accuracy of the numerical calculations. This integral has the following form:

$$
\begin{aligned}
& I=\sum_{m=1}^{M} \frac{\varepsilon_{m}^{2}}{2}+\frac{N_{1}}{N} \overline{V_{e}}-\Lambda \cdot \frac{N_{2}}{N} \bar{V}=\sum_{m=1}^{M} \frac{\varepsilon_{m}^{2}}{2}+ \\
& +\frac{1}{N} \cdot \sum_{i=1}^{N_{1}} \frac{d \xi_{i}}{d \tau}-\frac{\Lambda}{N} \sum_{i=N_{1}+1}^{N} \frac{d \xi_{i}}{d \tau}=\cos t .
\end{aligned}
$$

System (7) - (9) satisfies the condition of the particle coordinate's periodicity - the equations do not change when replaced $\zeta_{i} \rightarrow \zeta_{i}+2 \pi k$. In addition, there is the following symmetry of the amplitudes and phases of the field: $\varepsilon_{-m}=-\varepsilon_{m}, \phi_{-m}=-\phi_{m}$.

The system of equations (7) - (9) was investigated numerically using the method of bunches particles modeling by large particles [1, 10 - 12] with the following values of the counting parameters: the number of modes $M=50 \ldots 100$; the initial coordinates of the electron layers $\zeta_{i}$ are distributed on the $(0 \ldots 2 \pi)$ interval in the form of two large particles (the number of layers is $N=$ 2 ); the initial distribution of the amplitudes of the wave disturbances was set to be uniform with the initial values of the amplitudes $\mathcal{E}_{m}=10^{-2}$ and phases $\phi_{m}=10^{-3}$ for all values of $m$.

\section{NUMERICAL SIMULATION RESULTS}

Let us discuss the results of numerical simulation of the interaction of particles of two types with a plasma corrugated waveguide's dense wave spectrum. The choice of one decrement value for two types of particles in equation (7) indicates that we have chosen such system parameters for which the interaction occurs in the same forbidden band.

The ratio of the number of test particles in the bunch, which is accelerated, and electrons in the bunch, which generates oscillations in the waveguide, is determined by the parameter $\theta=N_{1} / N_{2}$ [15]. First, as a test calculation, consider the acceleration of such test particles as positrons. Let the number of particles in bunches be: $\theta=1$.

In Fig. 3 the time variations of the average velocity of the test particle $\bar{V}$, electron bunch $\overline{V_{e}}$, and integral of the system of equations in the absence of absorption $(\mathrm{d}=0) I$ are shown. In the calculations it was assumed that the initial velocities of the particles are the same.

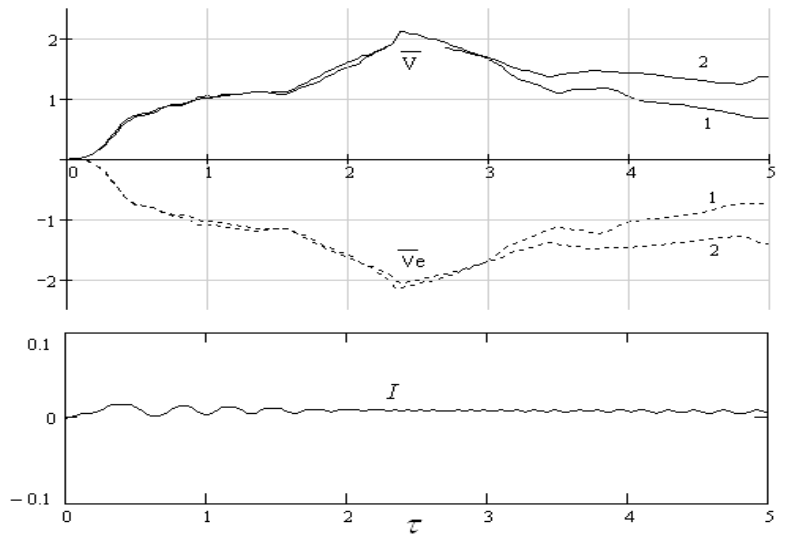

Fig. 3. Dependence of the average velocities of the test particle $\bar{V}$ and the electron bunch $\overline{V_{e}}$ on the dimensionless time $\tau: 1-d=0,0 ; 2-d=0.2$

It can be seen from the figure that there is a synchronous change in the average velocities of the test particle and the electron bunch. In the absence of absorption, the integral remains almost unchanged, which indicates the reliability of the obtained numerical results.

Let's now consider the acceleration of a heavy $(\Lambda>>1)$ positively charged particle.

In Fig. 4 shows the temporal dynamics of the average velocities of particles which move in a corrugated plasma waveguide.

In the numerical simulation, the following parameter values were specified: $M=50 ; N=2 ; d=0.2 ; \Lambda=10$ at the same initial particle velocities.

It follows from the figure that at the beginning of the interaction, the average velocity of the accelerating particles increases more slowly than the main bunch loses. In the absence of absorption, the integral of the system changes by a relatively small value at $\tau \leq 2.5$, i.e. at such time intervals when acceleration of test particles is observed. 

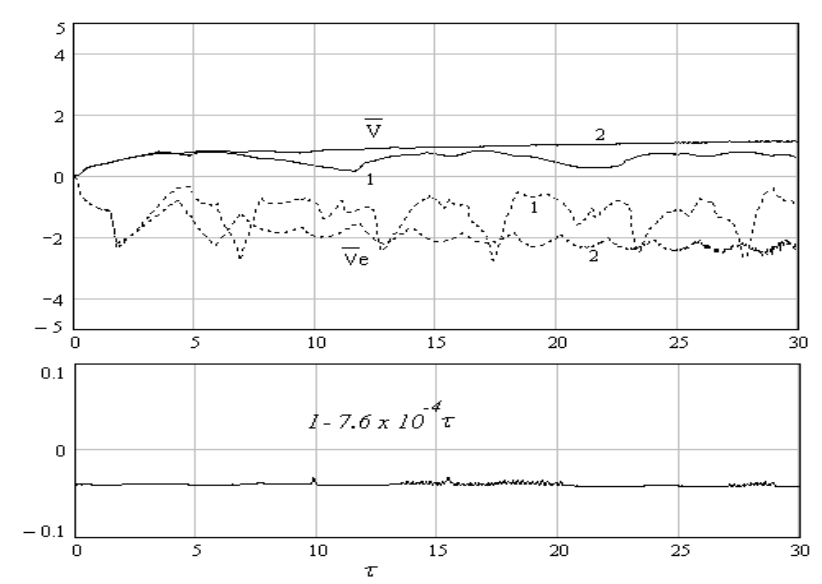

Fig. 4. Dependence of average velocities of a heavy test particle $\bar{V}$ and electron bunch $\overline{V_{e}}$ on dimensionless

time $\tau: 1-d=0 ; 2-d=0.2$

The difference between the energies of these bunches is concentrated in the internal energy of the plasma and in the energy of the oscillations.

The above examples of test particles acceleration are made for cases when the initial velocities of particles of two types are comparable. This explains the small value of the change in the average velocity of the test particle. If the initial velocity of the test particle is less than the initial velocity of the electron bunch, then the average momentum of the test particle may increase twice. This is indicated by numerical calculations, the result of one of which is shown in Fig. 5.
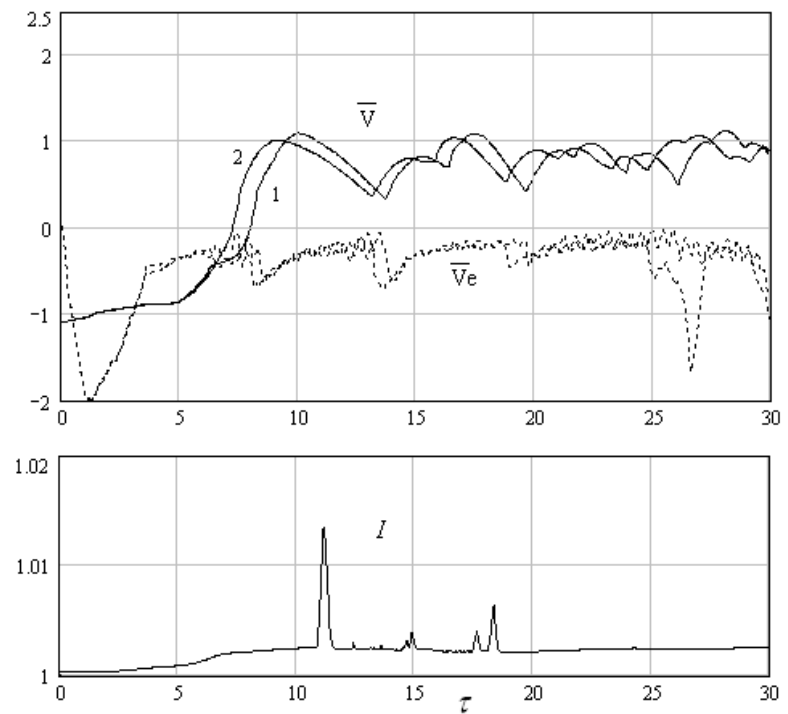

Fig. 5. Dependence of average velocities of a heavy test particle $\bar{V}$ and an electron bunch $\overline{V_{e}}$ on dimensionless time $\tau: 1-d=0 ; 2-d=0.02$

Calculations carried out for different values of the initial velocities of the test particle and the accelerated bunch, show that the greatest increase in the average speed of the test particle is observed at the initial speed of the test particle $d \varsigma /\left.d \tau\right|_{\tau=0}=-1.1$. The results of such a calculation are shown in Fig. 5. The same increase in the average velocity was established in a test calculation for positrons. For large values of the initial velocity $d \varsigma /\left.d \tau\right|_{\tau=0}>-1.1$ the acceleration of the test particle is not observed. Smaller values of the initial velocity lead to a small change in the average velocity of the test particle. Accounting for the absorption of oscillations in the forbidden band (see Figs. 4, 5, curve 2 ) increases the acceleration rate of the test particle.

Let's now estimate the length at which the acceleration of the test particles is observed, and compare with the result of the analysis of the wave spectrum corrugated plasma waveguide.

Based on the results of calculations shown in Fig. 1, one can estimate the acceleration length of the test particle. It is determined by the ratio $L_{1} \approx 100 \cdot L_{0}=2 \pi \cdot 100 \cdot k_{0}^{-1}$. On the other hand, the acceleration distance of the test particle, obtained as a result of numerical calculations, gives the dimensionless acceleration time $\tau \approx 9 \ldots 10$, which, in terms of the distance passed by the main bunch, gives the acceleration length $L_{2}=10 \cdot k_{3}^{-1}$. A comparison of these values makes it possible to state that the acceleration distances are of the same order already at the plasma density $\beta^{1 / 3} \approx 0.05$.

\section{CONCLUSIONS}

It is shown that in a corrugated superconducting plasma-filled waveguide, it is possible to use a two-step mechanism for the acceleration of charged particles. The first step is the excitation of a corrugated plasma waveguide with a short electron bunch in the direction of the longitudinal movement (the length of the bunch is significantly less than the period of the corrugation). The second step is the acceleration of test charged particles in an electric field excited by an electron bunch of an infinite number of harmonics. Calculations show that with the implementation of such an acceleration mechanism, the average velocity of a test non-relativistic particle may increase several times.

A system of equations which describes a two-step method of the charged particles acceleration is obtained.

Test calculations show that the proposed acceleration mechanism ensures complete transfer of the electron bunch energy to the energy of a test particle of the same mass, but with a charge of opposite sign.

Numerical calculations have shown that the acceleration length of the test particle can be up to one meter (under $k_{0}=2 \pi / L_{0} \mathrm{~cm}^{-1}$ ) with a plasma density satisfying the condition $\beta^{1 / 3} \approx 0.05$.

\section{REFERENCES}

1. B.M. Bolotovskij. Teoriya effekta VavilovaCherenkova // UFN. 1957, t. 42, v. 3, p. 201-246 (in Russian).

2. V.A. Balakirev, N.I. Karbushev, A.O. Ostrovskij, Yu.V. Tkach. Teoriya cherenkovskih usilitelej i generatorov na relyativistskih puchkah. Kiev. "Naukova dumka”, 1993, 208 p. (in Russian).

3. V.A. Balakirev, V.I. Karas', I.M. Onishenko, et al. Doslidzhennya zbudzhennya kilvaternih poliv relyativistskimi elektronnimi zgustkami // UFZh. 1998, v. 43, iss. 9, p. 1160-1166 (in Ukrainian).

4. I.N. Onishenko. Charged particle acceleration by wakefields excited in dielectric waveguide by a 
sequence of electron bunches (overview) // Problems of Atomic Science and Technology. Series "Plasma Electronics and New Methods of Acceleration”. 2004, № 4, p. 97-103.

5. N.A. Azarenkov, I.V. Tkachenko, V.I. Tkachenko. Features of dispersive characteristics of axisymmetric electromagnetic waves of magnetoactive plasma taking place in the ideally conducting waveguide with finit depth of a ripple // Problems of Atomic Science and Technology. Series "Plasma Electronics and New Methods of Acceleration". 2008, № 4, p. 54-59.

6. N.A. Azarenkov, I.V. Tkachenko, V.I. Tkachenko. Shodyashiesya beskonechnye opredeliteli $\mathrm{v}$ issledovaniyah periodicheskih plazmennyh volnovodov i analiz ih vliyaniya na dispersiyu elektromagnitnyh voln // Visnik Harkivskogo nacionalnogo universitetu. Seriya «Matematichne modelyuvannya. Informacijni tehnologiyi. Avtomatizovani sistemi upravlinnya». 2010, № 926, v. 15, p. 11-24 (in Russian).

7. V.I. Lapshin, O.F. Stoyanov, I.V. Tkachenko, V.I. Tkachenko. Obchislennya dispersijnih harakteristik plosko paralelnogo gofrovanogo plazmovogo hvilevodu // Visnik Lviv. universitetu. Seriya fizichna. 2006, v. 39, p. 160-162 (in Ukrainian).

8. V.I. Lapshyn, I.V. Tkachenko, V.I. Tkachenko. Peculiarities of dispersion characteristics of sinusoidally rippled plasma waveguides with small ripple depth // Problems of Atomic Science and Technology. Series "Plasma Physics”. 2003, № 1, p. 89-91.
9. V.I. Lapshyn, A.F. Stoyanov, I.V. Tkachenko, V.I. Tkachenko. Fractal Properties of Dispersion Characteristics of Sinusoidally Rippled Plasma Waveguide // Problems of Atomic Science and Technology. Series “Plasma Physics”. 2005, № 1, p. 137-139.

10. I.G. Maciborko, I.N. Onishenko, Ya.B. Fajnberg, et al. O vozniknovenii turbulentnosti pri vzaimodejstvii «monoenergeticheskogo» puchka s plazmoj // ZhETF. 1972, v. 62, iss. 3(9), p. 874 (in Russian).

11. A.A. Ivanov. Fizika silnoneravnovesnoj plazmy. M.: "Atomizdat", 1977, 347 p. (in Russian).

12. A.N. Kondratenko, V.M. Kuklin. Osnovy plazmennoj elektroniki. M.: "Energoatomizdat", 1988, 320 p. (in Russian)

13. V.I. Tkachenko, P.V. Turbin. Dinamika volnovogo spektra v puchkovo-plazmennyh sistemah // Elektromagnitnye volny $i$ elektronnye sistemy. 2000, v. 5, № 1, p. 24-29 (in Russian).

14. D.A. Andronov, V.I. Tkachenko. Dinamika volnovyh processov $\mathrm{v}$ dissipativnyh puchkovoplazmennyh sistemah // Visnik HNU im. V.N. Karazina, № 529, “Yadra, chastinki, polya. 2001, v. 3/15/, p. 47-49 (in Ukrainian).

15. I.V. Tkachenko, V.I. Tkachenko. Uskorenie zaryazhennyh chastic $\mathrm{V}$ gofrirovannyh plazmennyh volnovodah s idealno provodyashimi stenkami // Tez. dokladov XIV konferenciya po fizike vysokih energij, yadernoj fizike i uskoritelyam. Kharkiv, NSC KIPT, 2016, p. 82 (in Russian).

Article received 03.06.2019

\section{ФРАКТАЛЬНЫЙ УСКОРИТЕЛЬ НА ОСНОВЕ ГОФРИРОВАННОГО ПЛАЗМЕННОГО ВОЛНОВОДА СО СВЕРХПРОВОДЯЩИМИ СТЕНКАМИ}

\section{И.В. Ткаченко, В.И. Ткаченко}

Предложено использование двухступенчатого механизма ускорения заряженных частиц. Принцип ускорения основан на использовании фрактальных свойств волнового спектра гофрированного плазменного волновода со сверхпроводящими стенками. Первая ступень обеспечивает возбуждение гофрированного плазменного волновода короткими в направлении движения электронными сгустками (длина сгустка значительно меньше периода гофра). Вторая ступень осуществляет ускорение пробных заряженных частиц в возбужденном электронными сгустками бесконечном по количеству гармоник электрическом поле. Расчеты показывают, что при реализации такого механизма ускорения средняя скорость нерелятивистской пробной частицы может увеличиваться в несколько раз, а длина ее ускорения может составлять расстояние до одного метра.

\section{ФРАКТАЛЬНИЙ ПРИСКОРЮВАЧ НА ОСНОВІ ГОФРОВАНОГО ПЛАЗМОВОГО ХВИЛЕВОДУ 3 НАДПРОВІДНИМИ СТІНКАМИ}

\section{І.В. Ткаченко, В.І. Ткаченко}

Запропоновано використання двоступеневого механізму прискорення заряджених частинок. Принцип прискорення заснований на використанні фрактальних властивостей хвильового спектра гофрованого плазмового хвилеводу з надпровідними стінками. Перший ступінь забезпечує збудження гофрованого плазмового хвилеводу короткими в напрямку руху електронними згустками (довжина згустку значно менше періоду гофра). Другий ступінь здійснює прискорення пробних заряджених частинок у збудженому електронними згустками нескінченному за кількістю гармонік електричному полі. Розрахунки показують, що при реалізації такого механізму прискорення середня швидкість нерелятивістської пробної частинки може збільшуватися в кілька разів, а довжина її прискорення може становити відстань до одного метра. 